\title{
Comparison of first-generation EGFR-TKIs (gefitinib, erlotinib, and icotinib) as adjuvant therapy in resected NSCLC patients with sensitive EGFR mutations
}

\author{
Qihua He ${ }^{1,2 \#}$, Jun Liu ${ }^{1,2 \#}$, Xiuyu Cai ${ }^{3 \#}$, Miao He ${ }^{1,2}$, Caichen $\mathrm{Li}^{1,2}$, Hengrui Liang ${ }^{1,2}$, Bo Cheng ${ }^{1,2}$, \\ Xiaojun Xia ${ }^{1,2}$, Minzhang Guo ${ }^{4}$, Peng Liang ${ }^{1,2}$, Ran Zhong ${ }^{1,2}$, Feng Li $^{1,2}$, Ziwen Yu ${ }^{1,2}$, Yi Zhao ${ }^{1,2}$, \\ Limin $\mathrm{Ou}^{1,2}$, Shan Xiong ${ }^{1,2}$, Jianfu $\mathrm{Li}^{1,2}$, Jianrong Zhang ${ }^{5,6}$, Jianxing $\mathrm{He}^{1,2}$, Wenhua Liang ${ }^{1,2,7}$ \\ ${ }^{1}$ Department of Thoracic Surgery and Oncology, The First Affiliated Hospital of Guangzhou Medical University, Guangzhou, China; ${ }^{2}$ Guangzhou \\ Institute of Respiratory Disease \& China State Key Laboratory of Respiratory Disease \& National Clinical Research Center for Respiratory Disease, \\ Guangzhou, China; ${ }^{3}$ Department of General Internal Medicine, Sun Yat-sen University Cancer Center, Guangzhou, China; ${ }^{4}$ Department of \\ Thoracic Surgery, West China Hospital, West China School of Medicine, Sichuan University, Chengdu, China; ${ }^{5}$ Cancer in Primary Care Research \\ Group, Centre for Cancer Research; Department of General Practice, Melbourne Medical School, Faculty of Medicine, Dentistry and Health \\ Sciences, University of Melbourne, Melbourne, Australia; ${ }^{6}$ Victorian Comprehensive Cancer Centre, Melbourne, Victoria, Australia; ${ }^{7}$ Department of \\ Medical Oncology, The First People's Hospital of Zhaoqing, Zhaoqing, China \\ Contributions: (I) Conception and design: W Liang, J He; (II) Administrative support: W Liang, J He; (III) Provision of study materials or patients: \\ Q He, J Liu, X Cai; (IV) Collection and assembly of data: Q He, J Liu, X Cai; (V) Data analysis and interpretation: All authors; (VI) Manuscript \\ writing: All authors; (VII) Final approval of manuscript: All authors. \\ \#These authors contributed equally to this work. \\ Correspondence to: Wenhua Liang, Jianxing He. Department of Thoracic Surgery and Oncology, The First Affiliated Hospital of Guangzhou Medical \\ University, Guangzhou Institute of Respiratory Disease \& China State Key Laboratory of Respiratory Disease, No. 151, Yanjiang Rd, Guangzhou \\ 510120, China. Email: liangwh@gird.cn; drjianxing.he@gmail.com.
}

Background: Several randomized controlled trials have suggested that adjuvant epidermal growth factor receptor (EGFR) tyrosine kinase inhibitors (TKIs) were associated with prolonged disease-free survival (DFS) in EGFR-mutated NSCLC patients after radical resection, comparing with chemotherapy or placebo. We aimed to compare the effectiveness of different first-generation EGFR-TKIs as adjuvant treatment in realworld setting.

Methods: Early-stage EGFR mutated NSCLC patients who underwent radical resection and treated with first-generation EGFR-TKIs (gefitinib, erlotinib, icotinib) as adjuvant therapy between Feb 2010 and Jan 2019 were retrieved from a prospectively-maintained database in our center. The primary endpoint was DFS in stage II/III (TNM 8th) patients with exploratory endpoint regarding DFS in stage I patients. Sensitivity analyses were based on propensity score matched (PSM) cohorts. Treatment failure patterns among different TKIs were also compared.

Results: Of 588 eligible patients, 198 patients (33.7\%) received gefitinib, 106 patients (17.9\%) received erlotinib, and 284 patients (48.2\%) received icotinib. The median DFS of stage II/III patients in the gefitinib, erlotinib and icotinib group were 36.1 months (95\% CI, 23.9-49.4), 42.8 months (95\% CI, 29.6-97.8), and 32.5 months (95\% CI, 23.9-49.4), respectively, with no significant difference (log-rank test $\mathrm{P}=0.22)$. There was also no significant difference in DFS among stage I patients receiving different TKIs (P=0.12). PSM adjustments and multivariate analyses adjusting for other confounders revealed similar results. In addition, there were no significant differences in treatment failure pattens in different EGFR-TKI arms, especially in terms of brain metastases $(6.1 \%$ in gefitinb, $7.5 \%$ in erlotinib, $3.9 \%$ in icotinib) and bone metastases $(8.6 \%$ in gefitinb, $9.4 \%$ in erlotinib, $7.0 \%$ in icotinib).

Conclusions: This first and largest real-world study showed that gefitinib, erlotinib, and icotinib demonstrated comparable clinical effectiveness as adjuvant therapy for patients with early-stage EGFR mutated NSCLC. 
Keywords: Non-small cell lung cancer (NSCLC); first-generation EGFR-TKIs; disease-free survival (DFS)

Submitted Aug 17, 2021. Accepted for publication Oct 20, 2021.

doi: $10.21037 /$ tlcr-21-649

View this article at: https://dx.doi.org/10.21037/tlcr-21-649

\section{Introduction}

In recently years, a significantly higher proportion of early stage non-small cell lung cancer (NSCLC) had been detected due to the usage of low-dose helical computed tomography (CT) in tumor screening (1). Nevertheless, even stage I NSCLC patients who undertook curativeintent resection was reported a $10.4 \%$ of 5 -year lung cancer-specific mortality (2). Platinum-doublet chemotherapy are standard adjuvant treatment for earlystage resected NSCLC, however, its efficacy was modest with a 5 -year absolute benefit of only in $5 \%$ (3). Better treatment strategies to improve the survival of those patients have been urgently expected by clinicians.

Several pivotal trials have revealed that epidermal growth factor receptor (EGFR) tyrosine kinase inhibitors (TKIs) were more effective than cytotoxic chemotherapy in the first-line treatment of advanced NSCLC with mutated EGFR (4-8). Subsequently, first generation EGFR-TKIs, such as erlotinib and gefitinib, have been demonstrated to improve the DFS of EGFR-mutant patients with resected early-stage lung cancers (9-11). Recently, a randomized phase III trial (ADJUVANT/CTONG1104) comparing gefitinib vs. chemotherapy in EGFR-mutant patients with completely resected NSCLC confirmed that adjuvant gefitinib achieved superior DFS than chemotherapy did (12). Thus, adjuvant EGFR-TKIs are now considered as a treatment option for resected NSCLC with sensitive EGFR mutations.

The first-generation EGFR-TKIs included icotinib, erlotinib and gefitinib. Previous trial has suggested no difference in progressive-free survival (PFS) among different first-generation EGFR-TKIs in advanced NSCLC patients harboring EGFR mutations (13). However, in EGFR-mutant NSCLC patients after radical resection, it is still unclear whether different first-generation EGFRTKIs can affect DFS as adjuvant treatment. Therefore, we performed a retrospective study to compare the clinical efficacy among three first-generation EGFR-TKIs as adjuvant treatment for EGFR-mutant NSCLC patients who underwent curative-intent resection.

We present the following article in accordance with the
STROBE reporting checklist (available at https://dx.doi. org/10.21037/tlcr-21-649).

\section{Methods}

\section{Study design}

This is a retrospective study of a prospectively maintained cohort. The aims of this study were to compare the efficacy among three first-generation EGFR-TKIs as adjuvant treatment and the recurrence pattern in patients with completely resected EGFR-mutant NSCLC. The study was conducted in accordance with the Declaration of Helsinki (as revised in 2013). The study was approved by the Institutional Ethical Committee for Clinical Investigation of First Affiliated Hospital of Guangzhou Medical University (ethical No. 2015). Every patient informed consent was collected before surgery.

\section{Patients and treatments}

Inclusion criteria for the patients in this study were as following: (I) consecutive patients with resected EGFRpositive NSCLC who received postoperative EGFR inhibitor at our hospital between February 2010 and January 2019 (II) treated with first-generation EGFR-TKIs. Patients were excluded if they underwent incompletely surgical resection [Chinese guidelines on the diagnosis and treatment of primary lung cancer (2019)], received radiotherapy or chemotherapy after surgery, or failed to have EGFR-TKI within two months after surgery. The dose of icotinib was $150 \mathrm{mg}$ tid, erlotinib was $150 \mathrm{mg} \mathrm{qd}$, and gefitinib was $250 \mathrm{mg}$ qd.

\section{Endpoints}

The primary endpoint was disease-free survival (DFS) in stage II/III (TNM 8th) patients with exploratory endpoint regarding DFS in stage I patients, which defined as time from having the resection surgery to documented disease relapse or death. Subgroup analyses were performed based on stage and EGFR mutation type. 
Follow-up

We undertook radiological assessments with CT every 3 months for the first 2 years after surgery, every 6 months over the next 3 years. The use of PET or MRI imaging or other clinical technical equipment for further evaluation of the disease was under the physician's discretion. Patients lost to follow-up were censored on the date of last imaging. Data collection was terminated on November 12, 2019.

\section{Identification of EGFR mutation}

Genetic analysis to determine EGFR mutation was performed by central laboratory testing using amplificationrefractory mutation system PCR. Additionally, next generation sequencing (NGS) was also applied to identify the EGFR mutation status.

\section{Statistical analysis}

$\mathrm{P}$ values were calculated based on Fisher's exact test for categorical variables and analysis of variance (ANOVA) for continuous variables in the baseline characteristics of patients. DFS curves were drawn using the Kaplan-Meier method, and statistical differences were calculated by a two-sided log-rank test. Values of $\mathrm{P}<0.05$ were considered as statistically significant. Hazard ratio (HR) and $95 \%$ CIs were estimated using a Cox proportional-hazards regression model. For the subgroup analysis, the same method was used to calculated DFS after categorizing the patients by age, sex, smoking status, stage, EGFR mutation status, lymph node status, and pathology. Multivariate Cox proportional hazards regression model was used to evaluate independent predictive factors associated with DFS. Propensity score matching (PSM) was used to adjust for known baseline characteristics. All statistical analyses were conducted using SPSS version 17.0 or SAS version 9.4 and plotting was made by $\mathrm{R}$ software version 3.6.0.

\section{Results}

\section{Patient characteristics}

A total of 588 EGFR-positive patients who underwent radical surgery of NSCLC were enrolled. Of those patients, 284 patients (48.2\%) received icotinib, 106 patients (17.9\%) received erlotinib and 198 patients $(33.7 \%)$ received gefitinib as adjuvant therapy. The median duration of treatment for icotinib, erlotinib and gefitinib were 17.7 months (range,
0.6-28.1 months), 20.1 months (range, 1.1-26.0 months) and 18.6 months (range, 0.5-28.8 months), respectively. The median age was 60 years (range, $26-80$ years) and 360 patients $(60.9 \%)$ were female; 565 patients $(95.6 \%)$ had adenocarcinoma and about three-quarters were nonsmokers. Regarding mutation type, 192 patients had a deletion in exon 19, 237 had a missense mutation in exon 21 (L858R), and 18 had other type of EGFR mutations. Most of the demographic characteristics were balanced between three treatment groups, while the icotinib-treated group had higher proportion of stage I disease patients (Table 1).

\section{DFS in stage II/III patients treated with each TKIs}

The median DFS was 50.8 months (95\% CI: 41.5-60.0) for all patients. Median DFS was 42.5 months (95\% CI: $29.9-$ 55.1) in gefitinib arm, 53.9 months (95\% CI: 33.1-74.6) in the erlotinib arm and 55.2 months (95\% CI: 41.2-69.2) in the icotinib arm, DFS was not statistically significantly different among the three arms in stage I-III patients (logrank test $\mathrm{P}=0.11$ ).

The median DFS of stage II/III patients in the gefitinib, erlotinib and icotinib group were 36.1 months (95\% CI: $23.9-$ 49.4), 42.8 months (95\% CI: 29.6-97.8), and 32.5 months (95\% CI: 23.9-49.4), respectively. There was no significant difference in DFS among three groups (log-rank test $\mathrm{P}=0.22$; Figure 1). Using Cox proportional hazards regression to adjust for possible confounders, our results showed that the HR of DFS for erlotinib versus icotinib was 0.85 (95\% CI: $0.45-1.58, \mathrm{P}=0.60$ ), and the HR of DFS for gefitinib versus icotinib was 1.25 (95\% CI: 0.74-2.12, $\mathrm{P}=0.41$ ) (Table 2). PSM adjustments revealed similar results (Supplementary material).

\section{Subgroup analysis and exploration analysis}

We also analyzed the DFS in three groups of patients with respect to various disease stage. In stage II subgroup, median DFS in patients treated with icotinib, erlotinib and gefitinib were $32.9,64.8$ and 30.1 months, respectively. In stage III population, median DFS in patients received with icotinib, erlotinib and gefitinib were 32.9, 40.3 and 36.7 months, respectively. The differences in DFS among three treatment groups were not significant regardless of disease stage (stage II, $\mathrm{P}=0.16$; stage III, $\mathrm{P}=0.96$ ) and EGFR mutation types (Exon 19 deletion, $\mathrm{P}=0.83$; Exon 21 Leu858Arg, $\mathrm{P}=0.23$ ) (Table 3, Figure 2).

In stage I subgroup, median DFS in patients treated with 
Table 1 Baseline characteristics of the study participants

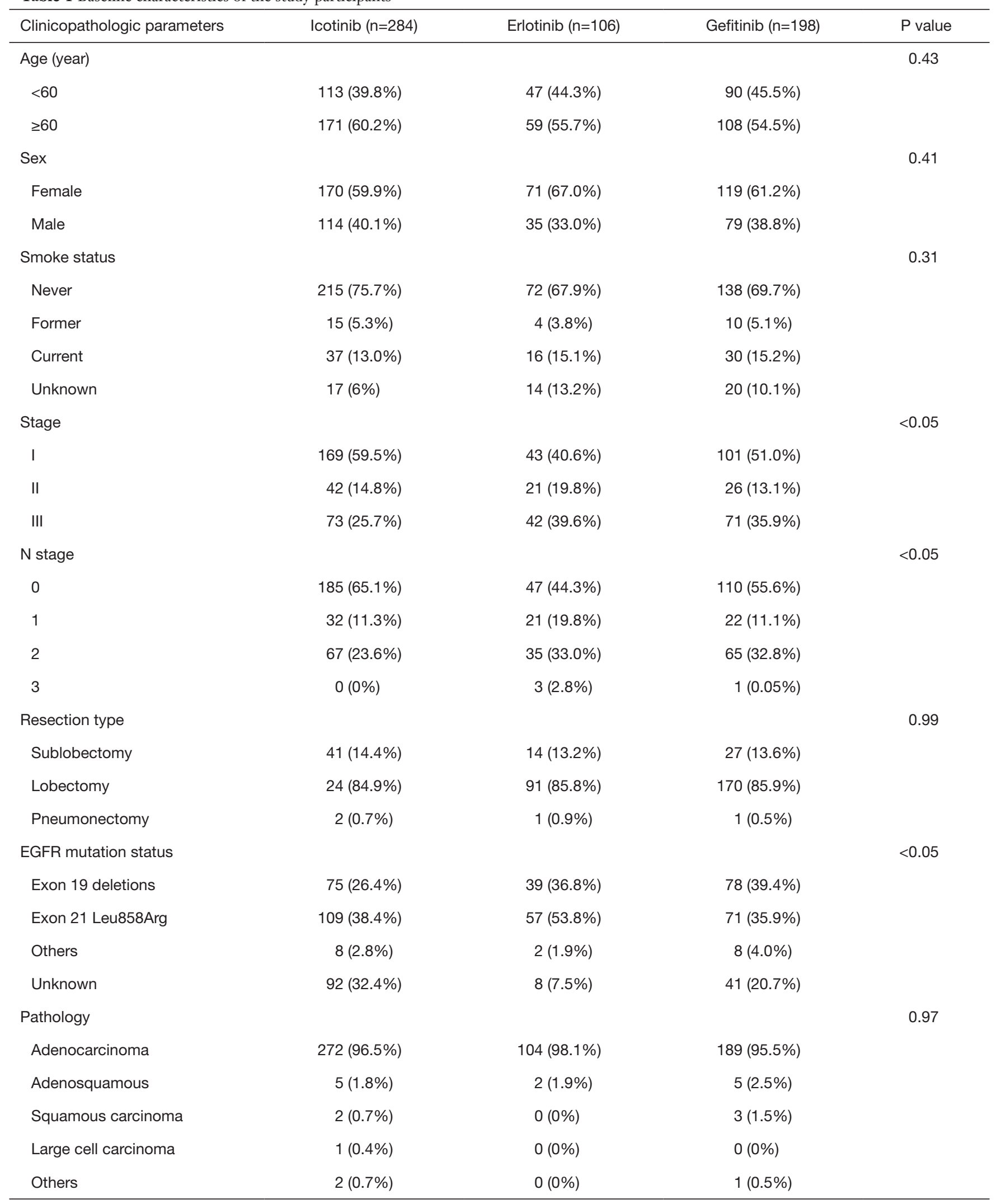



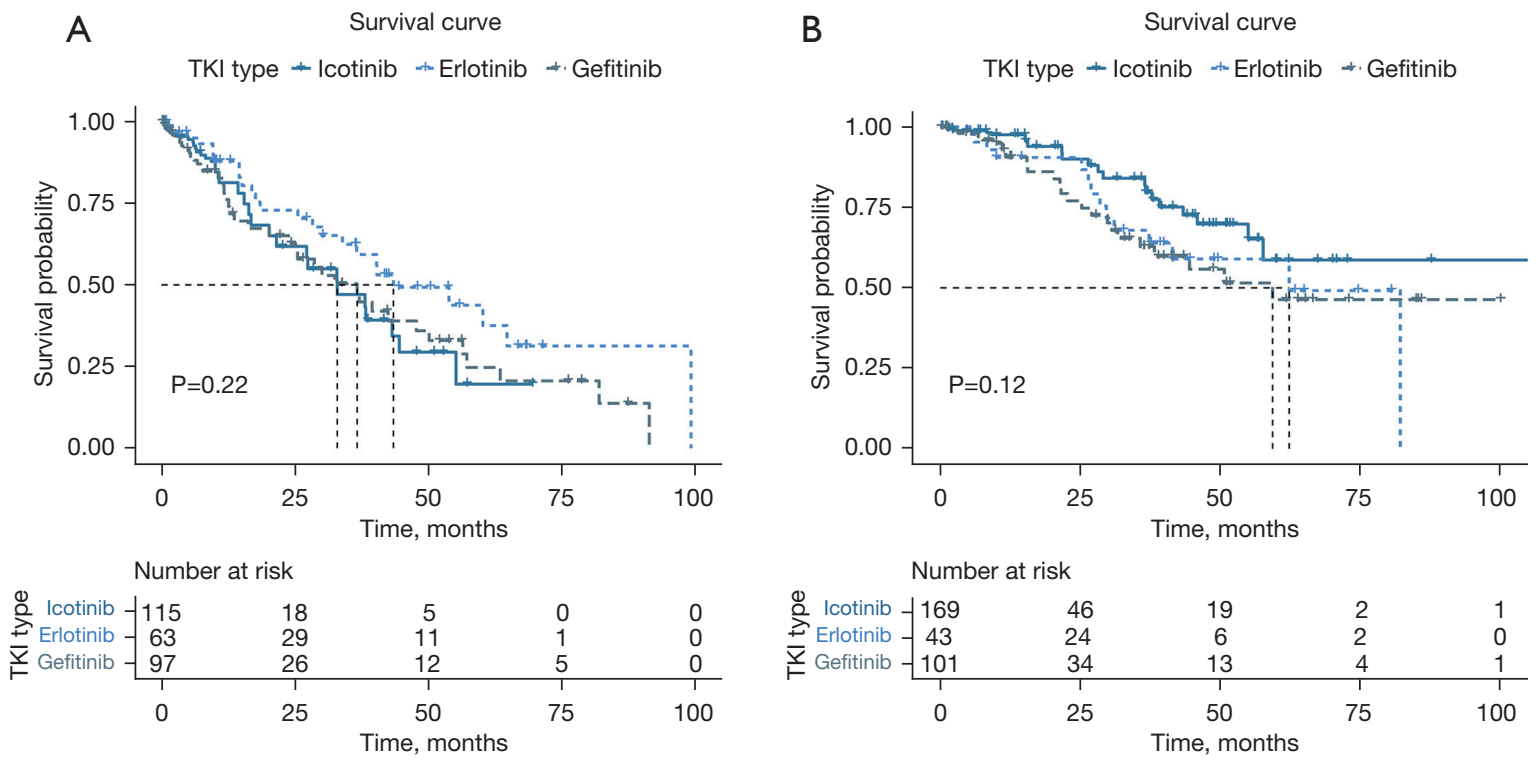

Figure 1 Kaplan-Meier curves for disease-free survival of (A) stage II/III and (B) stage I patients treating different TKIs. TKIs, tyrosine kinase inhibitors; HR, hazard ratio.

icotinib, erlotinib and gefitinib were not reached (NR), 62.4 and 59.4 months, respectively. Nevertheless, multivariant analysis revealed that erlotinib and gefitinib tend to have an inferior DFS than icotinib in stage I NSCLC patients (Table 3, Figure 1).

\section{Failure pattern analysis}

The most common sites of metastasis in overall population were lung $(9.8 \%)$, followed by bone $(8.0 \%)$, the central nervous system (CNS) (5.2\%), lymph node (3.4\%), the intra-abdominal region (1.7\%), pleural effusion $(0.8 \%)$ and liver $(0.8 \%)$ (Table 4$)$. A decreased incidence of lung metastasis was noted in the icotinib group [19 (6.7\%), 15 (14.2\%), 24 (12.1\%), respectively, $\mathrm{P}=0.038$ ]. Additionally, spatial-temporal treatment failure patterns did not differ among three treatment arms, in terms of brain metastases (6.1\% in gefitinb, $7.5 \%$ in erlotinib, $3.9 \%$ in icotinib) and bone metastases (8.6\% in gefitinb, $9.4 \%$ in erlotinib, $7.0 \%$ in icotinib), etc. (Table 4).

\section{Discussion}

EGFR-mutant NSCLC patients have achieved enormous benefits form TKI therapy regardless of disease stage. However, it is still urgent to further explore whether different TKIs result in diverse treatment outcomes. Our recent network analysis demonstrated that the efficacy of three first-generation EGFR-TKIs were showed to be similar for advanced NSCLC patients with EGFR mutation (14). Similarly, in this study regarding early stage, it was showed that DFS among three first-generation EGFR-TKIs did not differ in the adjuvant therapy of completely resected NSCLC patients with EGFR-positive. To the best of our knowledge, it is the first real-world study to compared the impact of three first-generation EGFRTKIs on radical resected early-stage NSCLC patients harboring EGFR mutations.

Previously, a meta-analysis including 5 randomized controlled trials demonstrated that adjuvant EGFR-TKIs had a better DFS compared to placebo and chemotherapy in EGFR-mutant NSCLC patients (13). In addition, two retrospective studies reported that adjuvant erlotinib or gefitinib presented a low rate of recurrence in resected stage I-III NSCLC with EGFR mutation $(10,15)$. In these evidences, TKIs were proved to be a promising option as an adjuvant therapy for selected patients with resected NSCLC. These evidences encouraged TKIs become a good option as an adjuvant therapy for selected patients. Up to now, there are three generations of EGFR inhibitors approved by the FDA to target this kinase, including firstgeneration (icotinib, erlotinib, gefitinib), second-generation (afatinib, dacomitinib) and third-generation (osimertinib). Our study revealed that no significant differences of DFS 
Table 2 Univariate and multivariate analysis of DFS in stage II/III patients

\begin{tabular}{|c|c|c|c|c|}
\hline Features & Univariate analysis & $P$ value & Multivariate analysis & $P$ value \\
\hline \multicolumn{5}{|l|}{ Age (year) } \\
\hline$<60$ & Reference & & Reference & \\
\hline$\geq 60$ & $1.12(0.75-1.69)$ & 0.58 & $1.13(0.72-1.78)$ & 0.59 \\
\hline \multicolumn{5}{|l|}{ Sex } \\
\hline Male & $2.10(1.38-3.18)$ & 0.0001 & $2.15(1.24-3.73)$ & 0.007 \\
\hline \multicolumn{5}{|l|}{ Smoke status } \\
\hline Never & Reference & & Reference & \\
\hline Former & $1.94(0.96-3.95)$ & 0.065 & $0.83(0.33-2.08)$ & 0.69 \\
\hline \multicolumn{5}{|l|}{ Resection type } \\
\hline Sublobectomy & Reference & & Reference & \\
\hline Lobectomy & $1.02(0.41-2.53)$ & 0.96 & $1.11(0.43-2.92)$ & 0.83 \\
\hline Pneumonectomy & $2.25(0.60-8.41)$ & 0.23 & $3.76(0.78-18.17)$ & 0.10 \\
\hline \multicolumn{5}{|l|}{ EGFR mutation status } \\
\hline Exon 19 deletions & Reference & & Reference & \\
\hline Exon 21 Leu858Arg & $1.29(0.81-2.05)$ & 0.28 & $0.99(0.59-1.66)$ & 0.97 \\
\hline Others & $2.34(0.98-5.59)$ & 0.056 & $2.40(0.94-6.17)$ & 0.07 \\
\hline
\end{tabular}

among three first-generation EGFR-TKIs as adjuvant treatment. However, safety and tolerability in our study were scarce.

To date, seven trials investigating EGFR-TKIs in the adjuvant setting have been completed and significant improved DFS with first-generation of EGFR-TKIs was observed in the EVAN (erlotinib versus chemotherapy), ADJUVANT (gefitinib versus chemotherapy) and EVIDENCE (icotinib versus chemotherapy) $(12,16,17)$. In addition, ADAURA trail conducted by $\mathrm{Wu}$ et al. showed Osimertinib yield a remarkable improvement DFS in earlystage, EGFR-mutant patients as adjuvant therapy compared with placebo (18). However, adjuvant chemotherapy (ACT) was involved in EGFT-TKI arm in ADAURA rather than in EVAN, ADJUVANT and EDVIDENCE trials. It remains unclear whether ACT could also contribute to the striking DFS benefit. Besides, unlike 3 years of duration in the ADAURA trial, duration of first-generation EGFR-TKIs was a maximum of 2 years. Further studies to elucidate whether longer treatment exposure of firstgeneration EGFR-TKIs would have positive impact on OS are warranted.

The subgroup results based on the disease stage and EGFR mutation status were similar to the overall outcome. However, multivariant analysis presented that gefitinib tend to have an inferior DFS than icotinib in stage I NSCLC 
Table 3 Exploration analysis and subgroup analysis

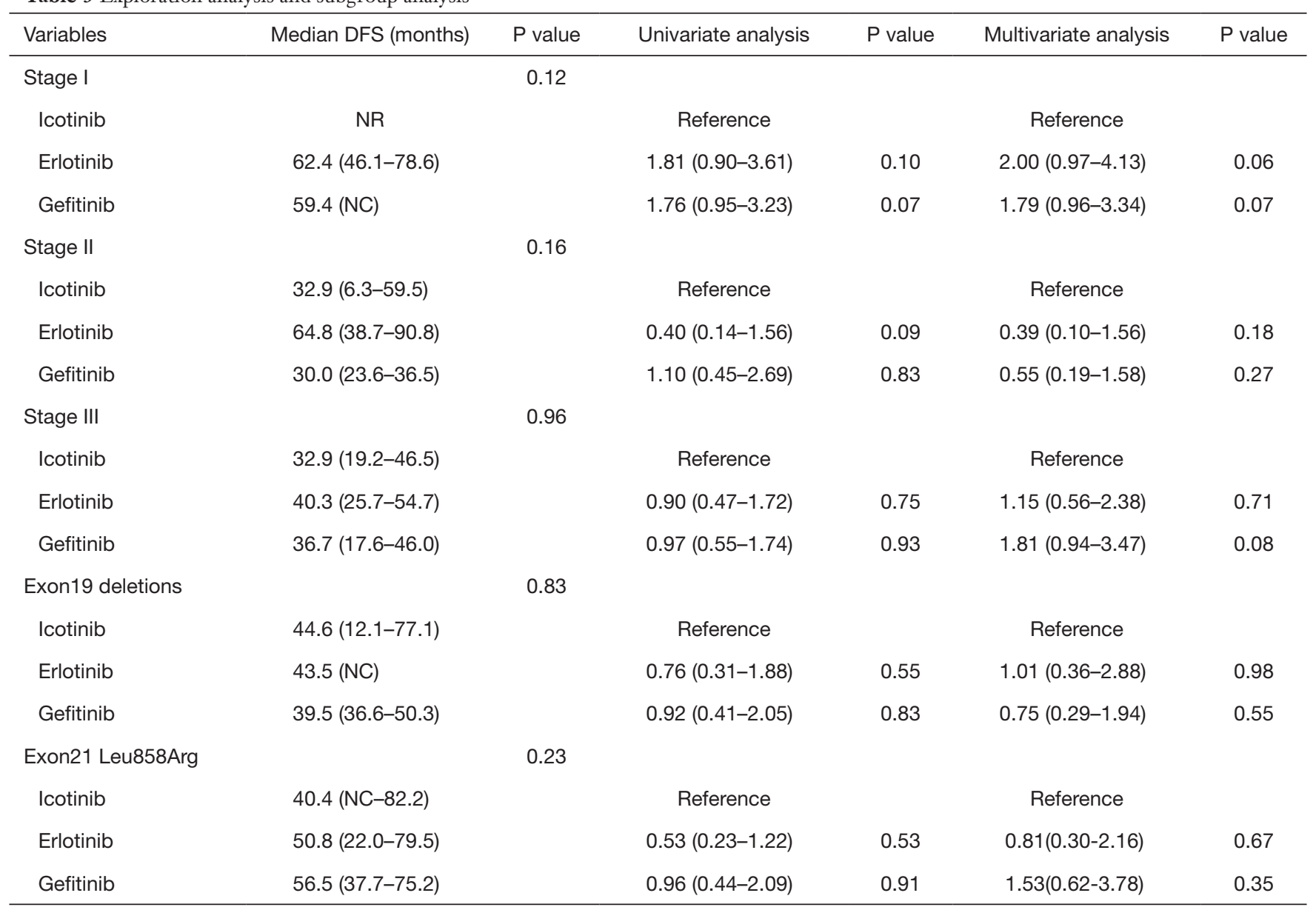

NR, not reached; NC, not calculable.

patients. The previous study reported $80 \% 5$-year survival for those patients with (p)stage IA disease and $72 \%$ for those with (p)stage IB NSCLC (19). It means that even patients with completely resected stage I NSCLC have a risk of recurrence. A meta-analysis in 2008 demonstrated adjuvant chemotherapy had a similar detrimental effect in patients with stage IA stage NSCLC (20). Moreover, the benefit of cytotoxic chemotherapy to stage IB disease remains controversial. Considering that adjuvant chemotherapy displayed limited improvements in survival of stage I NSCLC patients, adjuvant EGFR-TKIs might be an option for those patients harboring EGFR mutation.

Retrospective study conducted by Park et al. revealed that the most common recurrence sites for resected N1-stage II lung adenocarcinoma patients who received adjuvant platinum-based chemotherapy were lungs (48.9\%), followed by bone $(22.5 \%)$ and the brain (20.9\%) (21). Nevertheless, prospective study focusing on EGFR mutant patients, stage II-IIIA (N1-N2) NSCLC showed CNS metastases were the most common recurrence events in TKI group (27.4\%), while extracranial metastases accounted for the highest proportion of recurrence events in chemotherapy group (24.1\%) (22). Our study, including 588 patients with EGFR mutation-positive, stage I-III NSCLC, found that the most common site of metastasis was lung $(9.8 \%)$, followed by bone (8.0\%), CNS (5.2\%). There was no difference among three treatment groups in current study, but a decreased incidence of lung metastasis was noted in the icotinib group.

Limitations of our study include the fact that this is a retrospective analysis, prospective analysis is needed to further illustrate these issues. Another limitation is that, overall survival (OS) data were unmatured. However, whether different first-generation EGFR-TKIs had different effects on OS remained unclear. Besides, as 
A

A

Survival curve

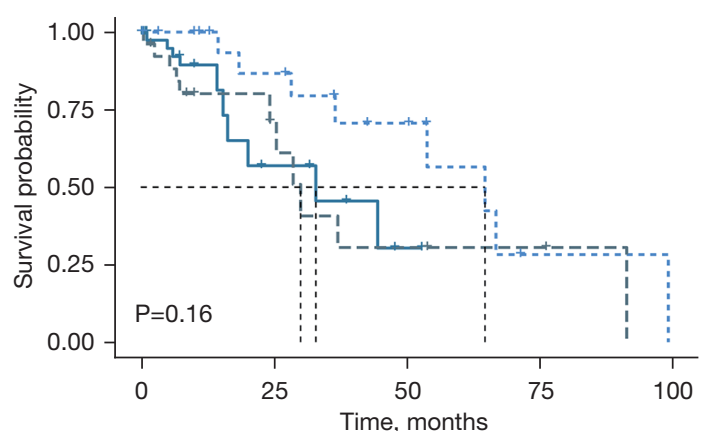

Number at risk

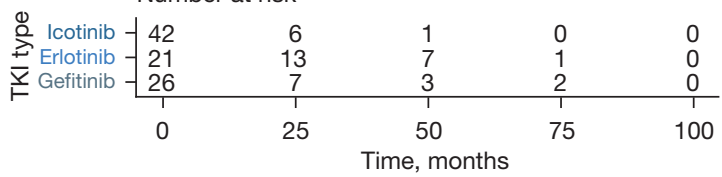

C

Survival curve

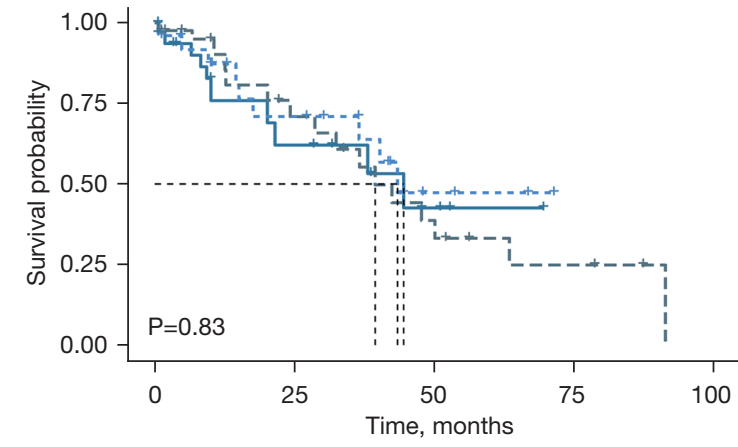

Number at risk

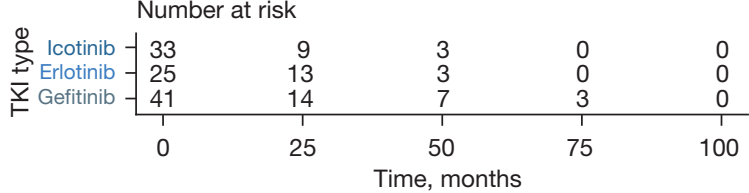

B Survival curve

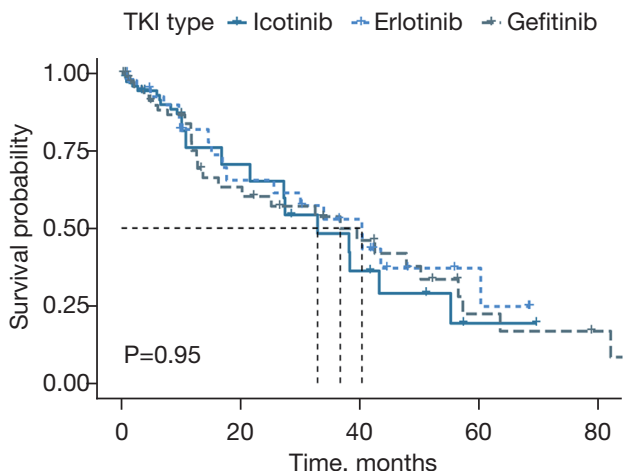

Number at risk

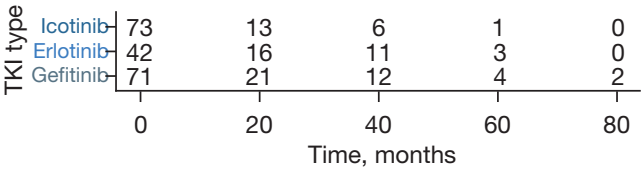

D Survival curve

TKI type - Icotinib - Erlotinib + Gefitinib

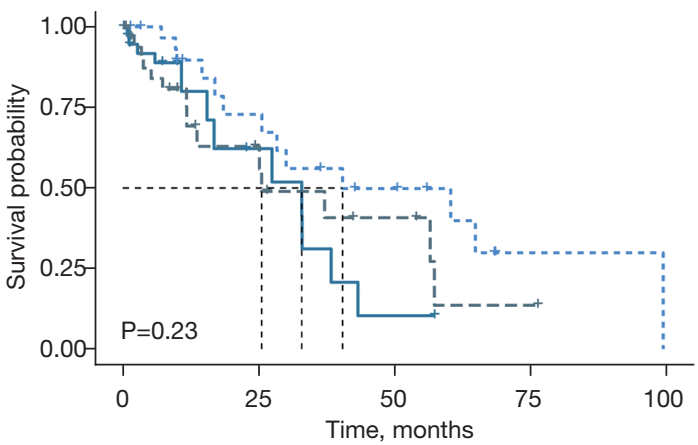

Number at risk

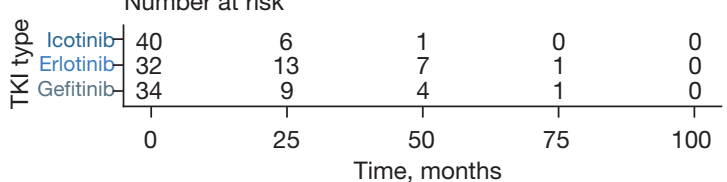

Figure 2 Kaplan-Meier curves of disease-free survival in (A) stage II, (B) stage III patients, (C) EGFR 19 del, and (D) EGFR 21 L858R subpopulations receiving different TKIs. TKIs, tyrosine kinase inhibitors; HR, hazard ratio.

Table 4 Failure patterns of different EGFR-TKIs

\begin{tabular}{|c|c|c|c|c|}
\hline Initial recurrence sites & Icotinib $(n=285)$ & Erlotinib $(n=106)$ & Gefitinib ( $n=199)$ & $P$ value \\
\hline Brain & $11(3.9 \%)$ & $8(7.5 \%)$ & $12(6.1 \%)$ & 0.29 \\
\hline Lung & $19(6.7 \%)$ & $15(14.2 \%)$ & $24(12.1 \%)$ & 0.04 \\
\hline Regional lymph nodes & $5(1.8 \%)$ & $6(5.7 \%)$ & $9(4.5 \%)$ & 0.09 \\
\hline Liver & $1(0.4 \%)$ & $2(1.9 \%)$ & $2(1.0 \%)$ & 0.38 \\
\hline Adrenal & $4(1.4 \%)$ & $1(0.9 \%)$ & $5(2.5 \%)$ & 0.52 \\
\hline
\end{tabular}


mentioned above, toxicity evaluation was absent in our study. Thus, we conducted multivariate analyses adjusting for confounders including treatment duration, and which showed similar results. Finally, treatment selection bias was inevitable in this study; however, since all patients received first-generation TKIs, the impact might be limited.

\section{Conclusions}

In summary, our study demonstrated that no DFS difference was observed among three first-generation EGFR-TKIs in patients with EGFR mutation-positive, radial resected, early-stage NSCLC. However, the data about safety and OS required further analysis.

\section{Acknowledgments}

We sincerely thank the patients who participated in this study. Besides, we would like to thank all authors for their efforts in making the study proceeded smoothly.

Funding: China National Science Foundation (Grant No. 82022048, 81871893), Key Project of Guangzhou Scientific Research Project (Grant No. 201804020030), High-Level University Construction Project of Guangzhou Medical University (Grant No. 20182737, 201721007, 201715907, 2017160107), National Key R\&D Program (Grant No. 2017YFC0907903 \& 2017YFC0112704) and the Guangdong High Level Hospital Construction "reaching peak" plan.

\section{Footnote}

Reporting Checklist: The authors have completed the STROBE reporting checklist. Available at https://dx.doi. org/10.21037/tlcr-21-649

Data Sharing Statement: Available at https://dx.doi. org/10.21037/tlcr-21-649

Conflicts of Interest: All authors have completed the ICMJE uniform disclosure form (available at https://dx.doi. org/10.21037/tlcr-21-649). WL serves as an unpaid Associate Editor-in-Chief of Translational Lung Cancer Research. The other authors have no conflicts of interest to declare.

Ethical Statement: The authors are accountable for all aspects of the work in ensuring that questions related to the accuracy or integrity of any part of the work are appropriately investigated and resolved. The study was conducted in accordance with the Declaration of Helsinki (as revised in 2013). The study was approved by the Institutional Ethical Committee for Clinical Investigation of First Affiliated Hospital of Guangzhou Medical University (ethical No. 2015). Every patient informed consent was collected before surgery.

Open Access Statement: This is an Open Access article distributed in accordance with the Creative Commons Attribution-NonCommercial-NoDerivs 4.0 International License (CC BY-NC-ND 4.0), which permits the noncommercial replication and distribution of the article with the strict proviso that no changes or edits are made and the original work is properly cited (including links to both the formal publication through the relevant DOI and the license). See: https://creativecommons.org/licenses/by-nc-nd/4.0/.

\section{References}

1. Kakinuma R, Muramatsu Y, Asamura H, et al. Low-dose CT lung cancer screening in never-smokers and smokers: results of an eight-year observational study. Transl Lung Cancer Res 2020;9:10-22.

2. Eguchi T, Bains S, Lee MC, et al. Impact of Increasing Age on Cause-Specific Mortality and Morbidity in Patients With Stage I Non-Small-Cell Lung Cancer: A Competing Risks Analysis. J Clin Oncol 2017;35:281-90.

3. Chemotherapy in non-small cell lung cancer: a metaanalysis using updated data on individual patients from 52 randomised clinical trials. Non-small Cell Lung Cancer Collaborative Group. BMJ 1995;311:899-909.

4. Maemondo M, Inoue A, Kobayashi K, et al. Gefitinib or chemotherapy for non-small-cell lung cancer with mutated EGFR. N Engl J Med 2010;362:2380-8.

5. Mitsudomi T, Morita S, Yatabe $Y$, et al. Gefitinib versus cisplatin plus docetaxel in patients with non-small-cell lung cancer harbouring mutations of the epidermal growth factor receptor (WJTOG3405): an open label, randomised phase 3 trial. Lancet Oncol 2010;11:121-8.

6. Mok TS, Wu YL, Yu CJ, et al. Randomized, placebocontrolled, phase II study of sequential erlotinib and chemotherapy as first-line treatment for advanced nonsmall-cell lung cancer. J Clin Oncol 2009;27:5080-7.

7. Rosell R, Carcereny E, Gervais R, et al. Erlotinib versus standard chemotherapy as first-line treatment for European patients with advanced EGFR mutation-positive 
non-small-cell lung cancer (EURTAC): a multicentre, open-label, randomised phase 3 trial. Lancet Oncol 2012;13:239-46.

8. Zhou C, Wu YL, Chen G, et al. Erlotinib versus chemotherapy as first-line treatment for patients with advanced EGFR mutation-positive non-small-cell lung cancer (OPTIMAL, CTONG-0802): a multicentre, open-label, randomised, phase 3 study. Lancet Oncol 2011;12:735-42.

9. D'Angelo SP, Janjigian YY, Ahye N, et al. Distinct clinical course of EGFR-mutant resected lung cancers: results of testing of 1118 surgical specimens and effects of adjuvant gefitinib and erlotinib. J Thorac Oncol 2012;7:1815-22.

10. Janjigian YY, Park BJ, Zakowski MF, et al. Impact on disease-free survival of adjuvant erlotinib or gefitinib in patients with resected lung adenocarcinomas that harbor EGFR mutations. J Thorac Oncol 2011;6:569-75.

11. Kelly K, Altorki NK, Eberhardt WE, et al. Adjuvant Erlotinib Versus Placebo in Patients With Stage IBIIIA Non-Small-Cell Lung Cancer (RADIANT): A Randomized, Double-Blind, Phase III Trial. J Clin Oncol 2015;33:4007-14.

12. Zhong WZ, Wang Q, Mao WM, et al. Gefitinib Versus Vinorelbine Plus Cisplatin as Adjuvant Treatment for Stage II-IIIA (N1-N2) EGFR-Mutant NSCLC: Final Overall Survival Analysis of CTONG1104 Phase III Trial. J Clin Oncol 2021;39:713-22.

13. Cheng H, Li XJ, Wang XJ, et al. A meta-analysis of adjuvant EGFR-TKIs for patients with resected non-small cell lung cancer. Lung Cancer 2019;137:7-13.

14. Zhao Y, Liu J, Cai X, et al. Efficacy and safety of first line treatments for patients with advanced epidermal growth factor receptor mutated, non-small cell lung

Cite this article as: He Q, Liu J, Cai X, He M, Li C, Liang H, Cheng B, Xia X, Guo M, Liang P, Zhong R, Li F, Yu Z, Zhao Y, Ou L, Xiong S, Li J, Zhang J, He J, Liang W. Comparison of first-generation EGFR-TKIs (gefitinib, erlotinib, and icotinib) as adjuvant therapy in resected NSCLC patients with sensitive EGFR mutations. Transl Lung Cancer Res 2021;10(11):41204129. doi: 10.21037/tlcr-21-649 cancer: systematic review and network meta-analysis. BMJ 2019;367:15460.

15. Pennell NA, Neal JW, Chaft JE, et al. SELECT: A Phase II Trial of Adjuvant Erlotinib in Patients With Resected Epidermal Growth Factor Receptor-Mutant Non-SmallCell Lung Cancer. J Clin Oncol 2019;37:97-104.

16. He J, Su C, Liang W, et al. Icotinib versus chemotherapy as adjuvant treatment for stage II-IIIA EGFR-mutant nonsmall-cell lung cancer (EVIDENCE): a randomised, openlabel, phase 3 trial. Lancet Respir Med 2021;9:1021-9.

17. Yue D, Xu S, Wang Q, et al. Erlotinib versus vinorelbine plus cisplatin as adjuvant therapy in Chinese patients with stage IIIA EGFR mutation-positive non-small-cell lung cancer (EVAN): a randomised, open-label, phase 2 trial. Lancet Respir Med 2018;6:863-73.

18. Wu YL, Tsuboi M, He J, et al. Osimertinib in Resected EGFR-Mutated Non-Small-Cell Lung Cancer. N Engl J Med 2020;383:1711-23.

19. Cerfolio RJ, Bryant AS. Survival of patients with true pathologic stage I non-small cell lung cancer. Ann Thorac Surg 2009;88:917-22; discussion 922-3.

20. Pignon JP, Tribodet H, Scagliotti GV, et al. Lung adjuvant cisplatin evaluation: a pooled analysis by the LACE Collaborative Group. J Clin Oncol 2008;26:3552-9.

21. Park BJ, Cho JH, Lee JH, et al. Temporal and regional distribution of initial recurrence site in completely resected N1-stage II lung adenocarcinoma: The effect of postoperative adjuvant chemotherapy. Lung Cancer 2018;117:7-13.

22. Xu ST, Xi JJ, Zhong WZ, et al. The Unique SpatialTemporal Treatment Failure Patterns of Adjuvant Gefitinib Therapy: A Post Hoc Analysis of the ADJUVANT Trial (CTONG 1104). J Thorac Oncol 2019;14:503-12. 


\section{Supplementary}

Total Sample Size $=588$ (Icotinib: erlotinib: gefitinib $=284: 106: 198)$

Median follow up time (months): Icotinib: erlotinib: gefitinib = 22.6:39.4:25.3

\section{Scenario 1}

Matching ratio $=1: 1: 1 ;$ Matched pairs $=95 ;$ all $\mathrm{p}$-values $>0.05$

Median follow up time after matching (months): Icotinib: erlotinib: gefitinib $=32.1: 41.0: 25.3$

\begin{tabular}{|c|c|c|c|c|c|}
\hline \multirow{2}{*}{ Variables } & \multirow{2}{*}{$\begin{array}{l}\text { P-value before } \\
\text { matching }\end{array}$} & \multicolumn{4}{|c|}{ After matching } \\
\hline & & Icotinib (N=95) & Erlotinib (N=95) & Gefitinib (N=95) & $p$-value \\
\hline Age group & 0.424 & & & & 0.750 \\
\hline$<60$ & & $45(47.4)$ & $41(43.2)$ & $46(48.4)$ & \\
\hline$>=60$ & & $50(52.6)$ & $54(56.8)$ & $49(51.6)$ & \\
\hline Sex & 0.408 & & & & 0.719 \\
\hline Female & & $57(60.0)$ & $62(65.3)$ & $57(60.0)$ & \\
\hline Male & & $38(40.0)$ & $33(34.7)$ & $38(40.0)$ & \\
\hline Smoke status & 0.301 & & & & 0.846 \\
\hline Never & & $60(63.2)$ & $67(70.5)$ & $64(67.4)$ & \\
\hline Former & & $4(4.2)$ & $4(4.2)$ & $2(2.1)$ & \\
\hline Current & & $21(22.1)$ & $14(14.7)$ & $19(20.0)$ & \\
\hline Unknown & & $10(10.5)$ & $10(10.5)$ & $10(10.5)$ & \\
\hline EGFR mutation status & $<0.001$ & & & & 0.930 \\
\hline Exon 19 deletions & & $32(33.7)$ & $35(36.8)$ & $39(41.1)$ & \\
\hline Exon 21 Leu85Arg & & $54(56.8)$ & $50(52.6)$ & $46(48.4)$ & \\
\hline Others & & $1(1.1)$ & $2(2.1)$ & $1(1.1)$ & \\
\hline Unkonwn & & $8(8.4)$ & $8(8.4)$ & $9(9.5)$ & \\
\hline Stage & 0.007 & & & & 0.774 \\
\hline I & & $44(46.3)$ & $43(45.3)$ & $41(43.2)$ & \\
\hline$\|$ & & $18(19.0)$ & $16(16.8)$ & $13(13.7)$ & \\
\hline III & & $33(34.7)$ & $36(37.9)$ & $41(43.2)$ & \\
\hline N Stage & 0.001 & & & & 0.814 \\
\hline 0 & & $52(54.7)$ & $47(49.5)$ & $44(46.3)$ & \\
\hline 1 & & $12(12.6)$ & $15(15.8)$ & $14(14.7)$ & \\
\hline 2 & & $31(32.6)$ & $33(34.7)$ & $37(39.0)$ & \\
\hline Resection type & 0.993 & & & & 0.761 \\
\hline Sublobectomy & & $14(14.7)$ & $12(12.6)$ & $10(10.5)$ & \\
\hline Lobectomy & & $80(84.2)$ & $82(86.3)$ & $85(89.5)$ & \\
\hline Pneumonectomy & & $1(1.1)$ & $1(1.1)$ & 0 & \\
\hline Pathology & 0.950 & & & & $>0.999$ \\
\hline Adenocarcinoma & & 94 (98.9) & $93(97.9)$ & $94(98.9)$ & \\
\hline Adenosquamous & & $1(1.1)$ & $2(2.1)$ & $1(1.1)$ & \\
\hline
\end{tabular}

P-values were calculated based on Fisher's exact test. 
A: Before matching

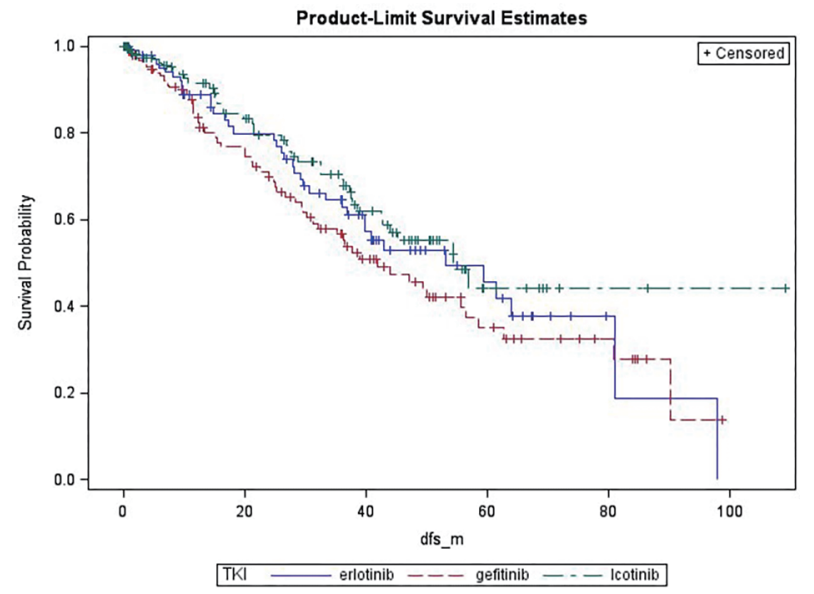

\begin{tabular}{lllllllll}
\hline & $\begin{array}{l}\text { Icotinib } \\
(\mathrm{N}=284)\end{array}$ & $\begin{array}{l}\text { Erlotinib } \\
(\mathrm{N}=106)\end{array}$ & $\begin{array}{l}\text { Gefitinib } \\
(\mathrm{N}=198)\end{array}$ & $\begin{array}{l}\text { Log-rank } \\
\mathrm{P} \text { value }\end{array}$ & $\begin{array}{l}\text { Icotinib } \\
(\mathrm{N}=95)\end{array}$ & $\begin{array}{l}\text { Erlotinib } \\
(\mathrm{N}=95)\end{array}$ & $\begin{array}{l}\text { Gefitinib } \\
(\mathrm{N}=95)\end{array}$ & $\begin{array}{l}\text { Log-rank } \\
\mathrm{P} \text { value }\end{array}$ \\
\hline Event, $\mathrm{n}(\%)$ & $49(17.3)$ & $39(36.8)$ & $63(31.8)$ & & $18(18.9)$ & $36(37.9)$ & $35(36.8)$ & \\
$\begin{array}{l}\text { Median DFS } \\
\begin{array}{l}(95 \% \mathrm{Cl}), \\
\text { months }\end{array}\end{array}$ & $\begin{array}{l}54.4(42.6, \\
\mathrm{NA})\end{array}$ & $\begin{array}{l}53.1(36.8, \\
81.1)\end{array}$ & $\begin{array}{l}41.9(30.2, \\
56.4)\end{array}$ & 0.112 & $\mathrm{NA}(37.6, \mathrm{NA})$ & $\begin{array}{l}53.1(36.8, \\
81.1)\end{array}$ & $\begin{array}{l}36.5(24.7, \\
56.4)\end{array}$ & 0.154 \\
\hline
\end{tabular}

B: After matching

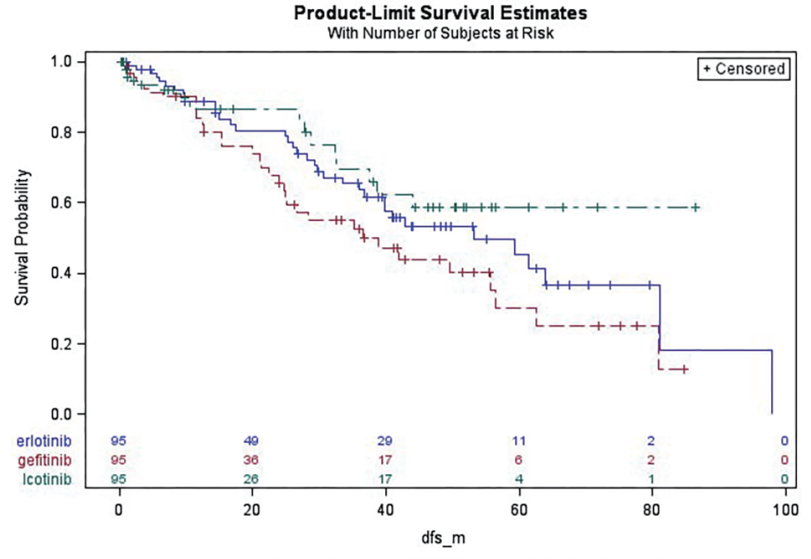

TKI $=$ erlotinit --- geffitinib $-\cdots-$ Icotinit

Subgroup analysis: Stage $=1$

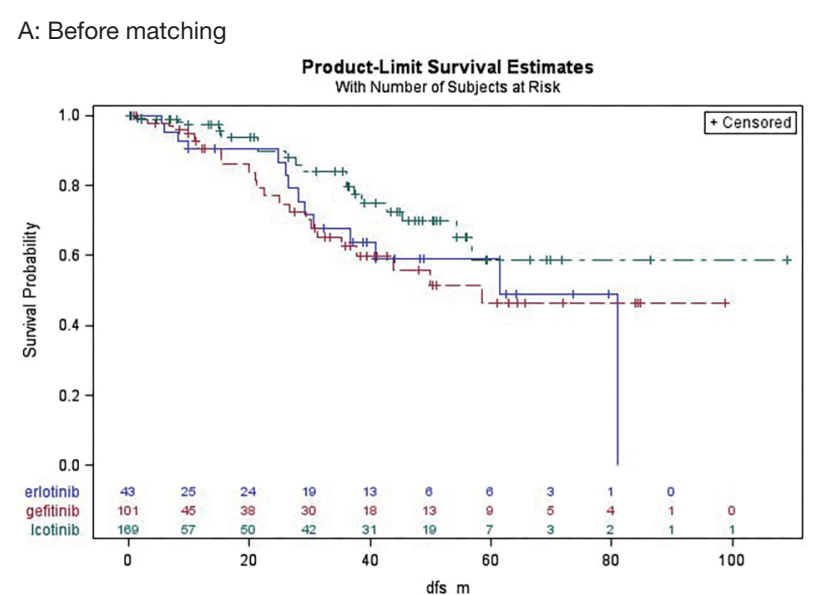

B: After matching

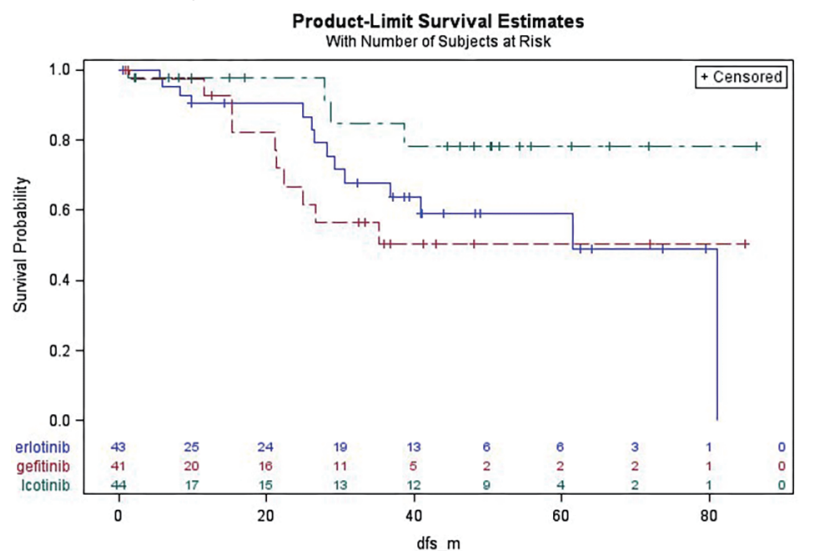

TKI $=$ erlotinilib --- geffitinib $-\cdots-$ Icotinib

\begin{tabular}{|c|c|c|c|c|c|c|c|c|}
\hline & $\begin{array}{l}\text { Icotinib } \\
(\mathrm{N}=169)\end{array}$ & $\begin{array}{l}\text { Erlotinib } \\
(\mathrm{N}=43)\end{array}$ & $\begin{array}{l}\text { Gefitinib } \\
(N=101)\end{array}$ & $\begin{array}{l}\text { Log-rank } \\
\mathrm{P} \text { value }\end{array}$ & $\begin{array}{l}\text { Icotinib } \\
(\mathrm{N}=44)\end{array}$ & $\begin{array}{l}\text { Erlotinib } \\
(\mathrm{N}=43)\end{array}$ & $\begin{array}{l}\text { Gefitinib } \\
(N=41)\end{array}$ & $\begin{array}{l}\text { Log-rank } \\
\mathrm{P} \text { value }\end{array}$ \\
\hline Event, n (\%) & $19(11.2)$ & $14(32.6)$ & $23(22.8)$ & & $4(9.1)$ & $14(32.6)$ & $10(24.4)$ & \\
\hline $\begin{array}{l}\text { Median DFS } \\
(95 \% \mathrm{Cl}), \\
\text { months }\end{array}$ & $\begin{array}{l}\text { NA (54.2, } \\
\text { NA) }\end{array}$ & $\begin{array}{l}61.5(30.6, \\
81.1)\end{array}$ & $\begin{array}{l}58.5 \text { (31.2, } \\
\text { NA) }\end{array}$ & 0.122 & NA $(38.6, N A)$ & $\begin{array}{l}61.5(30.6, \\
81.1)\end{array}$ & NA $(21.3, N A)$ & 0.134 \\
\hline
\end{tabular}

Subgroup analysis: Stage $=$ II or III

A: Before matching

Product-Limit Survival Estimates
With Number of Subjects at Risk

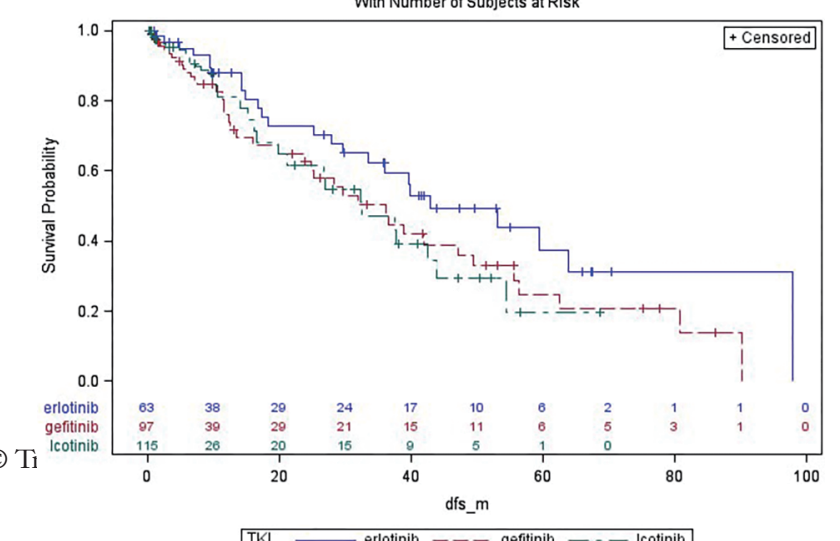

TK1 — errotinib --- geffinitb $-\cdots-$ Icotinit

\begin{tabular}{|c|c|c|c|c|c|c|c|c|}
\hline & $\begin{array}{l}\text { Icotinib } \\
(\mathrm{N}=115)\end{array}$ & $\begin{array}{l}\text { Erlotinib } \\
(\mathrm{N}=63)\end{array}$ & $\begin{array}{l}\text { Gefitinib } \\
(\mathrm{N}=97)\end{array}$ & $\begin{array}{l}\text { Log-rank } \\
\mathrm{P} \text { value }\end{array}$ & $\begin{array}{l}\text { Icotinib } \\
(\mathrm{N}=51)\end{array}$ & $\begin{array}{l}\text { Erlotinib } \\
(\mathrm{N}=52)\end{array}$ & $\begin{array}{l}\text { Gefitinib } \\
(\mathrm{N}=54)\end{array}$ & $\begin{array}{l}\text { Log-rank } \\
P \text { value }\end{array}$ \\
\hline Event, n (\%) & $30(26.1)$ & $25(39.7)$ & 40 (41.2) & & $14(27.5)$ & 22 (42.3) & $25(46.3)$ & \\
\hline $\begin{array}{l}\text { Median DFS } \\
(95 \% \mathrm{Cl}) \\
\text { months }\end{array}$ & $\begin{array}{c}32.5(19.9 \\
43.9)\end{array}$ & $\begin{array}{c}42.8(29.6 \\
97.8)\end{array}$ & $\begin{array}{c}36.1(23.9 \\
49.4)\end{array}$ & 0.223 & $\begin{array}{c}37.6(27.0 \\
\text { NA) }\end{array}$ & $\begin{array}{c}42.8(29.6 \\
63.8)\end{array}$ & $\begin{array}{c}36.5(19.9 \\
55.7)\end{array}$ & 0.431 \\
\hline
\end{tabular}

B: After matching

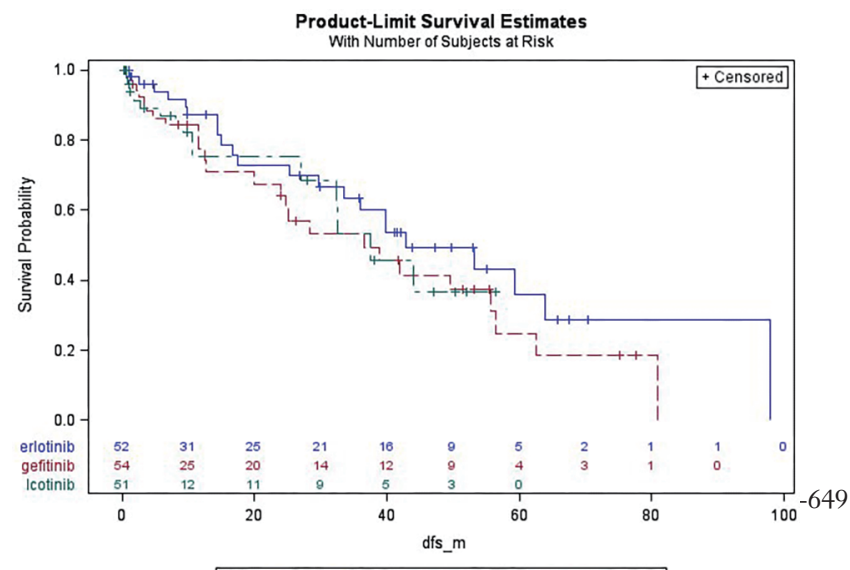

TKK _ erlotinib --- geffitinib $-\cdots-$ Icotinit

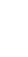


Scenario 2: treatment duration was included into logistic model as a covariate to calculate propensity score

Matching ratio $=1: 1: 1 ;$ Matched pairs $=92 ;$ all p-values $>0.05$

Median follow up time after matching (months): Icotinib: erlotinib: gefitinib = 20.7: 38.7: 24.0

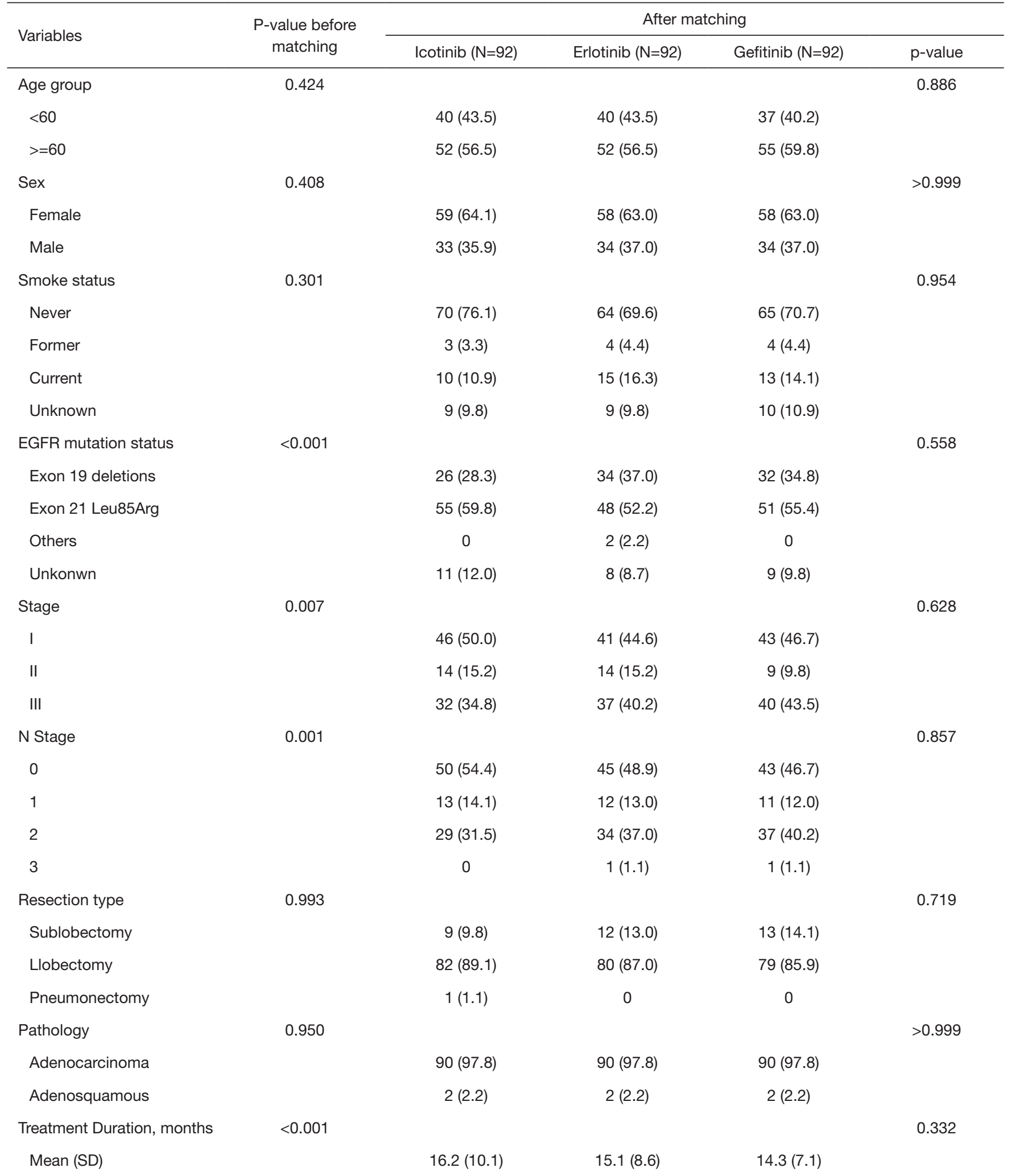

P-values were calculated based on Fisher's exact test for categorical variables and analysis of variance (ANOVA) for continuous variables. 
A: Before matching

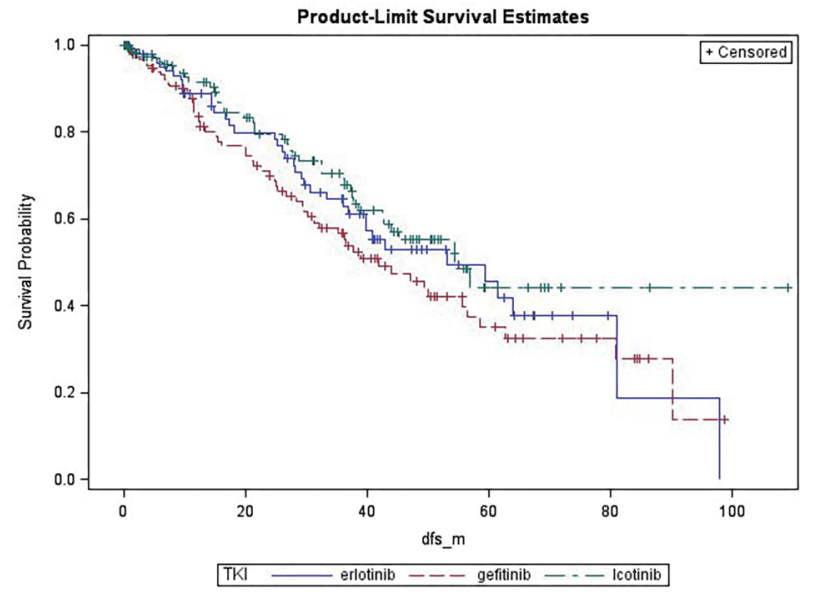

\begin{tabular}{lllllllll}
\hline & $\begin{array}{l}\text { Icotinib } \\
(\mathrm{N}=284)\end{array}$ & $\begin{array}{l}\text { Erlotinib } \\
(\mathrm{N}=106)\end{array}$ & $\begin{array}{l}\text { Gefitinib } \\
(\mathrm{N}=198)\end{array}$ & $\begin{array}{l}\text { Log-rank } \\
\mathrm{P} \text {-value }\end{array}$ & $\begin{array}{l}\text { Icotinib } \\
(\mathrm{N}=92)\end{array}$ & $\begin{array}{l}\text { Erlotinib } \\
(\mathrm{N}=92)\end{array}$ & $\begin{array}{l}\text { Gefitinib } \\
(\mathrm{N}=92)\end{array}$ & $\begin{array}{l}\text { Log-rank } \\
\mathrm{P} \text {-value }\end{array}$ \\
\hline Event, $\mathrm{n}(\%)$ & $49(17.3)$ & $39(36.8)$ & $63(31.8)$ & & $18(19.6)$ & $34(37.0)$ & $28(30.4)$ & \\
$\begin{array}{l}\text { Median DFS } \\
\begin{array}{l}(95 \% \mathrm{Cl}), \\
\text { months }\end{array}\end{array}$ & $\begin{array}{l}54.4(42.6, \\
\mathrm{NA})\end{array}$ & $\begin{array}{l}53.1(36.8, \\
81.1)\end{array}$ & $\begin{array}{l}41.9(30.2, \\
56.4)\end{array}$ & 0.112 & $\mathrm{NA}(42.6, \mathrm{NA})$ & $\begin{array}{l}53.1(30.6, \\
81.1)\end{array}$ & $\begin{array}{l}49.4(29.4, \\
\mathrm{NA})\end{array}$ & 0.077 \\
\hline
\end{tabular}

B: After matching

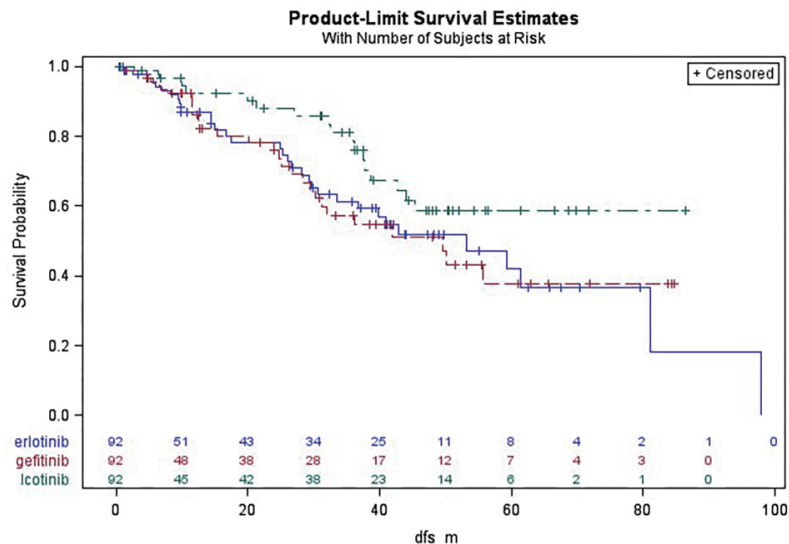

dis_m
--- geffiniti --- Icotinib
nat -

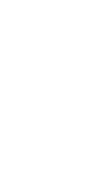

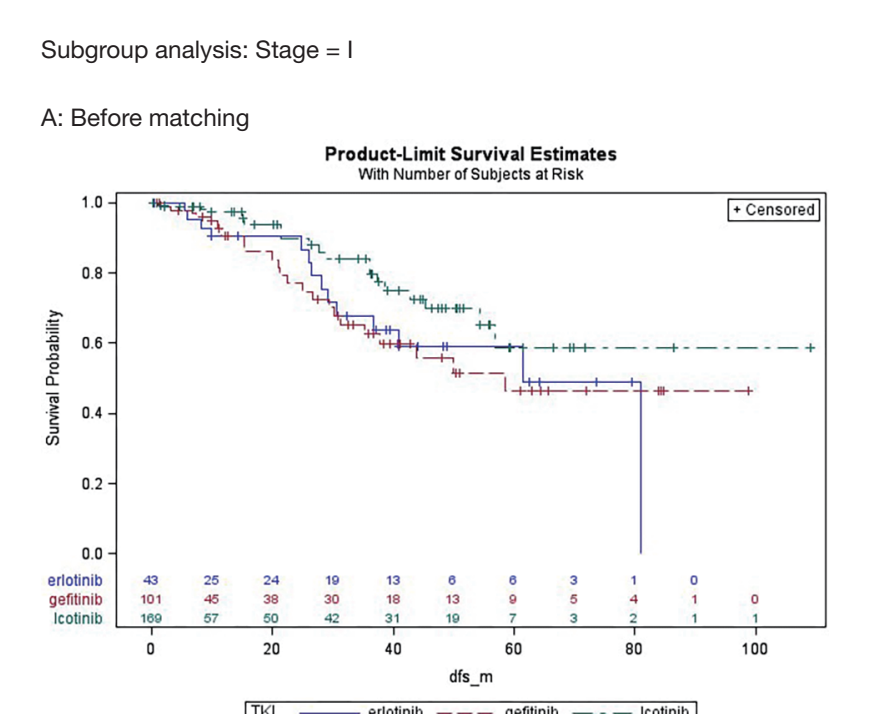

B: After matching

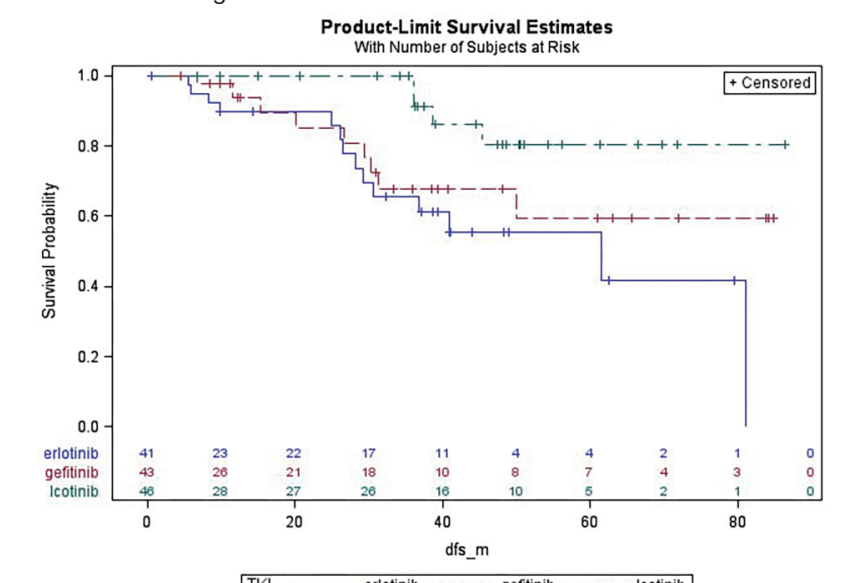

TK1 erlotinib --- geffitinis ---1 Icotinib

\begin{tabular}{|c|c|c|c|c|c|c|c|c|}
\hline & $\begin{array}{l}\text { Icotinib } \\
(\mathrm{N}=169)\end{array}$ & $\begin{array}{l}\text { Erlotinib } \\
(\mathrm{N}=43)\end{array}$ & $\begin{array}{l}\text { Gefitinib } \\
(\mathrm{N}=101)\end{array}$ & $\begin{array}{l}\text { Log-rank } \\
\text { P-value }\end{array}$ & $\begin{array}{l}\text { Icotinib } \\
(\mathrm{N}=46)\end{array}$ & $\begin{array}{l}\text { Erlotinib } \\
(\mathrm{N}=41)\end{array}$ & $\begin{array}{l}\text { Gefitinib } \\
(\mathrm{N}=43)\end{array}$ & $\begin{array}{l}\text { Log-rank P- } \\
\text { value }\end{array}$ \\
\hline Event, $\mathrm{n}(\%)$ & 19 (11.2) & $14(32.6)$ & $23(22.8)$ & & $4(8.7)$ & $14(34.1)$ & $9(20.9)$ & \\
\hline $\begin{array}{l}\text { Median DFS } \\
(95 \% \mathrm{Cl}), \\
\text { months }\end{array}$ & $\begin{array}{l}\text { NA (54.2, } \\
\text { NA) }\end{array}$ & $\begin{array}{l}61.5(30.6, \\
81.1)\end{array}$ & $\begin{array}{l}58.5 \text { (31.2, } \\
\mathrm{NA})\end{array}$ & 0.122 & $N A(N A, N A)$ & $\begin{array}{l}61.5(29.2, \\
81.1)\end{array}$ & $N A(31.2, N A)$ & 0.011 \\
\hline
\end{tabular}

Subgroup analysis: Stage = II or III

A: Before matching

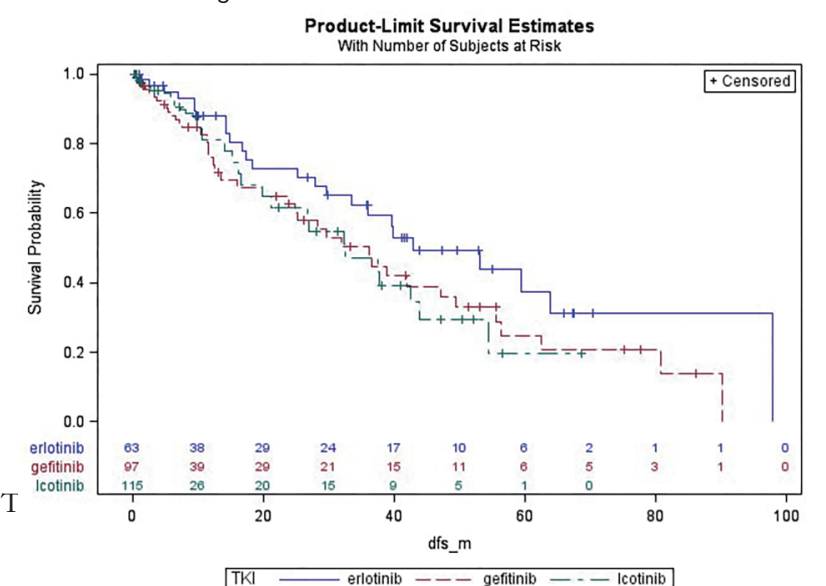

TKI $=$ erlotinib --- geffinits ---1 Icotinib

\begin{tabular}{|c|c|c|c|c|c|c|c|c|}
\hline & $\begin{array}{l}\text { Icotinib } \\
(\mathrm{N}=115)\end{array}$ & $\begin{array}{l}\text { Erlotinib } \\
(\mathrm{N}=63)\end{array}$ & $\begin{array}{l}\text { Gefitinib } \\
(\mathrm{N}=97)\end{array}$ & $\begin{array}{l}\text { Log-rank } \\
\text { P-value }\end{array}$ & $\begin{array}{l}\text { Icotinib } \\
(\mathrm{N}=46)\end{array}$ & $\begin{array}{l}\text { Erlotinib } \\
(\mathrm{N}=51)\end{array}$ & $\begin{array}{l}\text { Gefitinib } \\
(\mathrm{N}=49)\end{array}$ & $\begin{array}{l}\text { Log-rank } \\
\text { P-value }\end{array}$ \\
\hline Event, n (\%) & $30(26.1)$ & $25(39.7)$ & 40 (41.2) & & $14(30.4)$ & $20(39.2)$ & $19(38.8)$ & \\
\hline $\begin{array}{l}\text { Median DFS } \\
(95 \% \mathrm{Cl}) \text {, } \\
\text { months }\end{array}$ & $\begin{array}{l}32.5(19.9 \\
43.9)\end{array}$ & $\begin{array}{l}42.8(29.6, \\
97.8)\end{array}$ & $\begin{array}{l}36.1 \text { (23.9, } \\
49.4)\end{array}$ & 0.223 & $\begin{array}{l}37.6(21.2, \\
\text { NA) }\end{array}$ & $\begin{array}{l}42.8(25.2 \\
97.8)\end{array}$ & $\begin{array}{l}32.0(23.9 \\
49.4)\end{array}$ & 0.442 \\
\hline
\end{tabular}

B: After matching

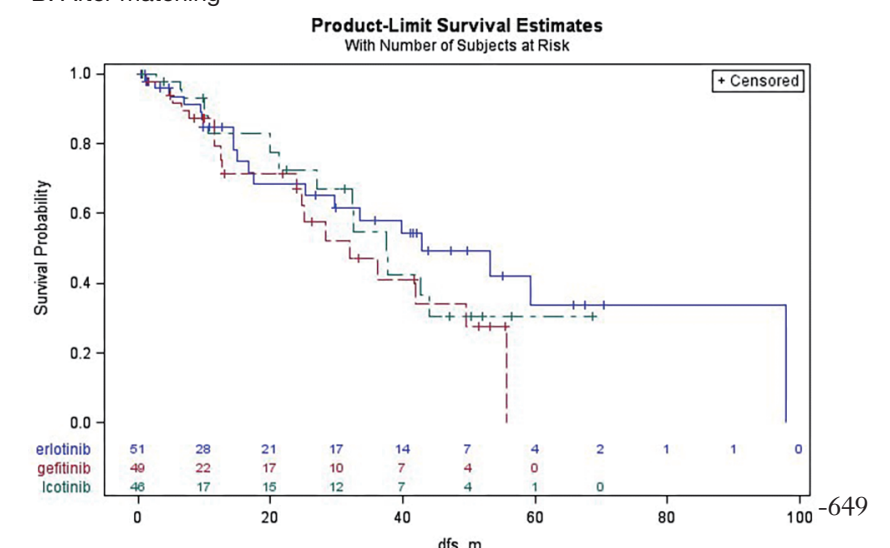

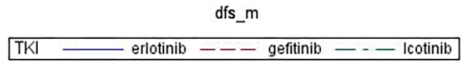
. 